\title{
Helicopter Ambulances in Critical Care
}

\author{
Sqn Ldr D R Andrew \\ FRCS(Glasg), RAF \\ Senior Registrar in Surgery
}

Princess Alexandra's Royal Air Force Hospital, Wroughton, Swindon, Wilts SN4 OQJ

SUMMARY: The origins of aeromedical transport lie in the ferrying of wounded soldiers to hospital. This pape outlines the history of aeromedical evacuation and examines American military and civil experience.

\section{Introduction}

Britain has been slow in developing helicopter ambulances, although the Armed Services have been using helicopters for rescue purposes for many years.

There is a drive to improve trauma management in Britain; the helicopter ambulance provides the ability to take advanced resuscitative techniques to the critically ill or injured patient, and to transport that patient quickly to the most appropriate hospital. The need for the helicopter within Britain's ambulance system is controversial but in some areas the speed and versatility of the helicopter makes it cost-effective.

\section{History}

The first reported aeromedical evacuation took place during the Franco-Prussian War of 1870-71, when balloons carried wounded soldiers from the besieged city of Paris (1). During World War 1, the British Army transported some casualties strapped on the rear fuselage of aircraft (Fig 1), and for the " $Z$ " Expedition to British Somaliland in 1920, the Royal Air Force modified a De Havilland 9 bomber to enable stretcher-borne patients to be carried in a chamber within the rear fuselage. This was the first dedicated ambulance aircraft (2).

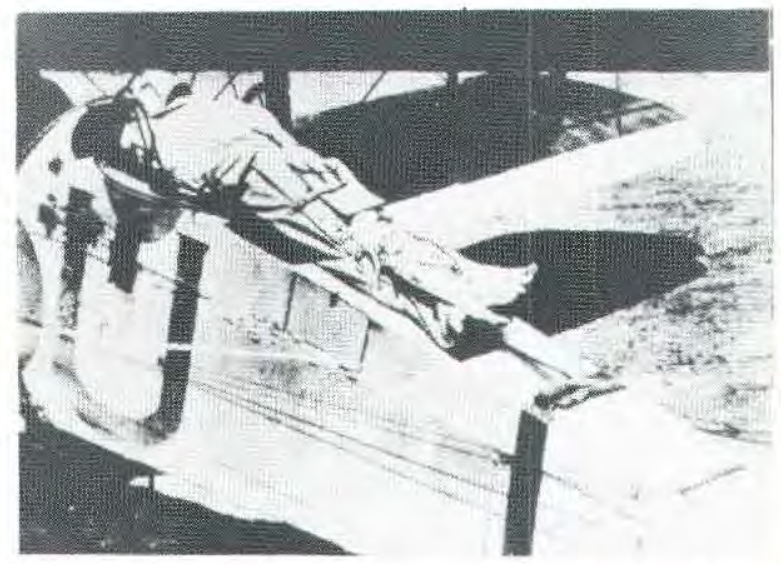

Fig 1. During WW1, there were rare instances of aircraft being used to evacuate casualties.
In 1945, the helicopter was first used for casualty evaco uation when an injured British soldier was lifted out of the Burma jungle by a US Army Sikorski aircraft (3). Durin $\vec{\varnothing}$ the Korean War, the 3rd Air Rescue Squadron, a United States Air Force helicopter unit tasked with recoverin aircrew who had ejected, used externally-mounted stretch ers to carry wounded soldiers (1). This expanded into network of rescue units, controlled by medical officers and with paramedics in the flight crews. Some 20,00莫 casualties were air-lifted during the Korean War. In Vie nam an efficient rescue service was developed wkoc became known by its radio call-sign "DUSTOFक्ळ" Between 1964 and 1969,370,000 wounded troops wetr airlifted to hospital by Dustoff helicopters (4). No com?at area in Vietnam was more than 35 minutes flying to away from a resuscitation unit $(5,6)$.

In comparison with earlier conflicts, helicopter tra port has been cited as a major factor in reducing the c\&us alty mortality rate $(3,7)$. The progressively more ragi transport of casualties coincides with a successive dro if mortality rate, which cannot be accounted for entirel advances in hospital management. For every 30 min delay in treatment of severely injured patients, the morta ity rate rises by $300 \%$ (5).

In the United States in the mid-1960s, Dustoff expertis was applied by the US Army to rescue casualties fror civil air accidents. This experiment, Operation Flatiror was expanded to include victims of Road Traffic Acce dents (RTA), and encouraging results led to the funding of several projects under the 1966 Highway Safet Act (5).

\section{Resuscitation}

Experience suggests that the prompt application effective resuscitation techniques is more important tha the early arrival of the patient at hospital $(3,7,8)$. By hav ing a doctor as an integral member of the flight teand definitive resuscitation and intervention can be instituteg earlier, preferably during the "golden hour" following injury. The medical officer should be a resuscitation of trauma specialist, assisted by a nurse or paramedi trained in Advanced Trauma Life Support and Advance Cardiac Life Support $(7,9)$. The helicopter medical tearor effectively extends the reach of the tertiary care hospitain Intervention at the scene of injury and during flight mañ 
include airway control by cricothyrotomy, tracheostomy or endotracheal intubation, assisted ventilation, insertion of chest drains, fluid and blood replacement, application of MAST trousers, and CPR $(1,3)$.

Studies of trauma viclim Iransport, collated by the American College of Surgeons Committee on Trauma, show a significant decrease in the mortality rate of patients transported by helicopter, compared with those moved by road ambulance (10). Baxt and Moody (11) compared the outcome of 150 patients in each group; the groups were matched for age, sex, Trauma Score (TS) and for the percentage of RTA victims $(86 \%)$. The patients transported by helicopter sustained a mortality rate $52 \%$ less than those in the group moved by road ambulance. Rhee et al (12) found that patients with TS between 10 and 5 have a greater chance of survival when transported by helicopter than those carried by road ambulance. No difference was found for casualties with TS over 10 , These findings suggest that patient selection is necessary to make the most effective use of helicopters. Most trauma victims can be dealt with in district hospitals, but some $5-10 \%$ benefit from the more aggressive treatment carried out in trauma centres (3). The helicopter ambulance integrates well with the trauma centre concept, being able to bypass local hospitals to carry the critically ill or injured patient to a specialised unit with more appropriate facilities.

\section{Modern Warfare}

The presence of a doctor on the helicopter is a luxury which cannot usually be afforded in wartime. However, as a result of their experiences of moving war casualties in the Six Day War in 1967 and the Yom Kippur War in 1973, the Isracli Defence Forces made elaborate preparations for the recovery of their wounded in the war in the Lebanon in 1982. Eighty-five percent of the Israeli casualties were ferried to hospital by dedicated helicopter ambulances, each of which carried a medical officer and

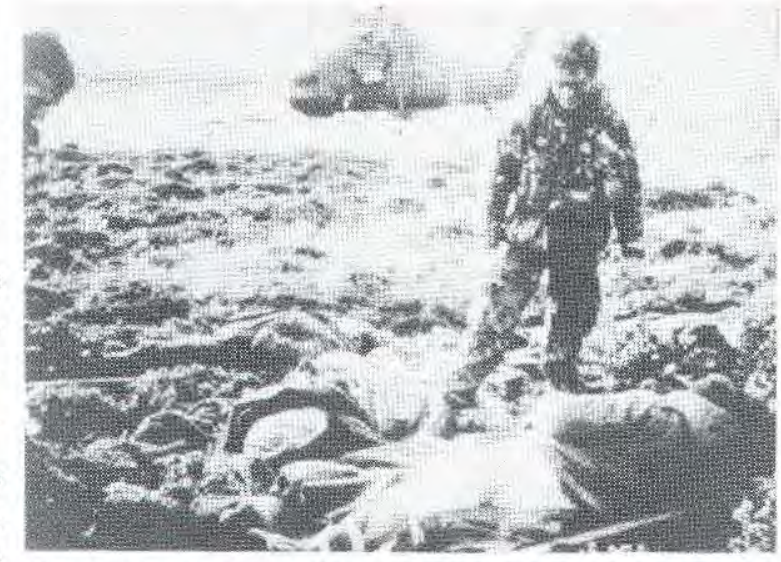

Fig 2. The terrain of the Falkland Islands made the helicopter the ideal vehicle for casualty evacuation. advanced resuscitation equipment - the Air Mobile Life Support Unit (AMLSU) (13). The hospitals used were civilian hospitals in Israel, prepared for the arrival of these soldiers. In contrast, in that same year, the British Forces involved in the Falklands War did not have access to civilian hospital facilities. The terrain of the Falkland Islands (Fig 2) meant that the ideal means of transferring casualties from battlefield to field hospital was by helicopter. These aircraft were not in the dedicated ambulance role but were used when they could be spared from their primary military tasks, although one machine was allocated for transferring severely injured casualties to the hospital ship (14). Air transportation allowed casualties to be brought to hospital within minutes of injury and was described by Admiral Sir John Fieldhouse as being a major contributory factor in maintaining a low mortality rate among the casualties (14).

During the Gulf War, the large distances involved meant that air transportation was again the most practical means of getting the casualties across desert terrain to the

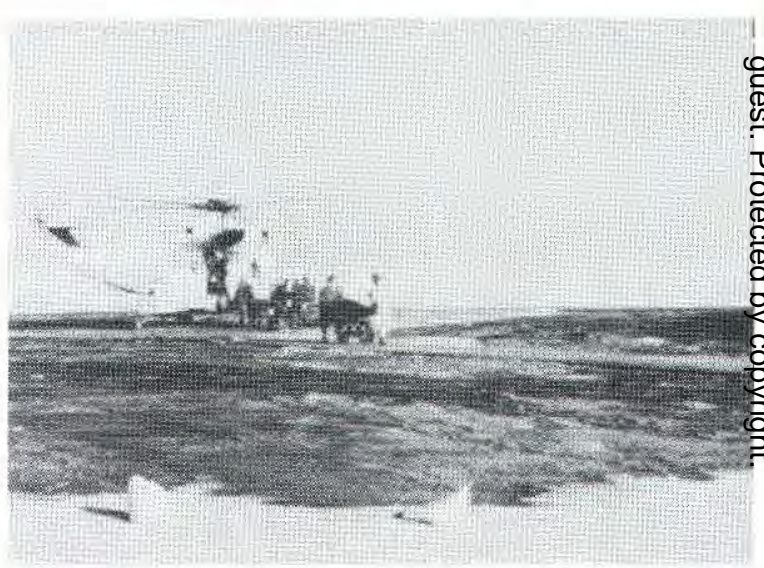

Fig 3. Helicopters were used extensively during Op Granby for casualty transportation.

field hospitals. Helicopters brought casualties to the forward field hospitals (Fig 3), while fixed wing aircraft conveyed them from there to hospitals in the rear.

\section{Peacetime Services}

In peacetime, Wessex and Sea King helicopters of the Royal Navy and Royal Air Force, together with Coastguard-controlled helicopters, provide a comprehensive Search and Rescue (SAR) helicopter network to cover the United Kingdom and its territorial waters (Fig 4). The primary role for the RAF and RN helicopters is the recovery of military aircrew, with a secondary role of providing assistance at civil aviation incidents. Ninety percent of SAR missions involve the rescue of civilians amounting to, on average, some 1000 persons per year. Whenever possible, SAR helicopters on rescue duties carry a medical officer. In disaster situations, the large cabin area 


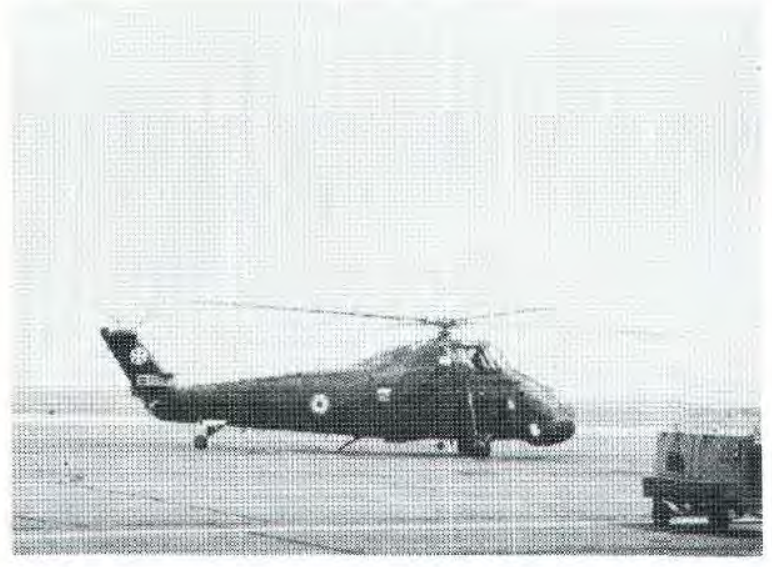

Fig 4. SAR missions involve the rescue of some 1000 persons per year.

allows rescue parties to be conveyed rapidly to the incident, and multiple casualties to be carried to hospital, but in general these large aircraft are not well suited to the peacetime role of helicopter ambulances.

\section{Civilian Programmes}

Dedicated civilian helicopter ambulance services in Britain started at Truro, Cornwall in 1987, with the First Air Ambulance (FAA). Because of the geography of Cornwall, with the outlying islands, the West Country is a difficult area to cover using conventional ambulances. From its base at Treliske Hospital the FAA can reach any part of Cornwall within 20 minutes (15). The helicopter improves the Ambulance Service's cost-effectiveness, doing the work of ten ambulances for the cost of seven $(15,16)$.

Other helicopter ambulance projects have been set up in Britain, including a trial of an airborne ITU for inter-hospital transfer, by personnel from St. Bartholomew's Hos-

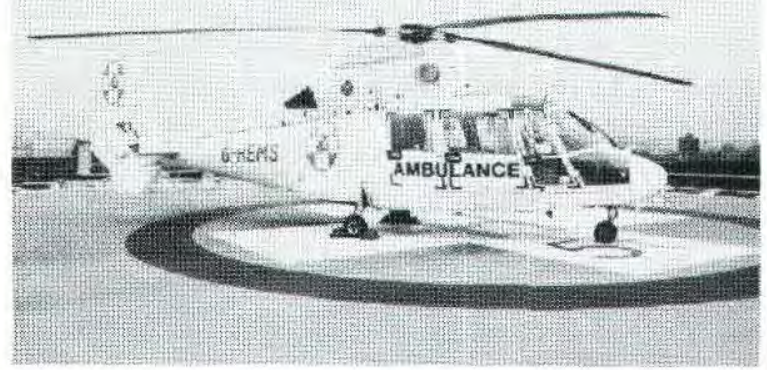

Fig 5. The Royal London Trust Hospital's helicopter integrates all DGHs and $A$ \& $\mathbf{E}$ units in the Thames Valley District. pital (17). One notable programme is the "HEMS" projeg t at the Royal London Trust Hospital (RLTH). This he copter ambulance (Fig 5) has been set up with thrge declared intentions: (i) to transport medical personnel (i) the scene of an accident, (ii) to airlift casualties to tofe most appropriate hospital and (iii) to integrate all DGlups and A\&E units in the Thames Valley District (18). T震 aircraft is controlled by the London Ambulance Servict and can reach any site inside the M25 motorway witlog ten minutes (18). A study is being carried out to evalua the improvement in trauma care brought about by toe addition of the helicopter ambulance and the RLT trauma unit.

\section{Discussion}

The helicopter has proved to be a most effective meas of transporting battle casualties to medical facilities time of war. However, this use imposes a heavy dema on helicopter resources in the field, and the helicopter can carry only a limited number of casualties. In a war w many hundreds of casualties, it would not be feasible $\phi$ employ helicopters as the sole means of casualty transfe $\vec{b}$

In peacetime, the application of this military corष्ट has been of value in providing a means of tan advanced medical help to the critically-ill or inj까엘 patient, and transporting that patient to the most apprọp Trate medical facility. However, helicopters are extre⿻日禸 expensive both to purchase and to operate, and in a seas?financed health system the costs may be considerg is outweigh the benefits. It is difficult to predict what $18 a$ the helicopter ambulance will eventually find in tre care in Great Britain, but perhaps the Armed Forces, 龅 their helicopters and hospitals staffed by trauma-traitris specialists, may have an important role to play.

\section{Acknowledgements}

I would like to thank Flt Lt Firmsher-Williams of Squadron, Royal Air Force Station Valley, Mr Richa尹্] Earlam and Lt Cdr T Spalding of the The Royal Lond $\bar{m}$ Hospital, and also Dr A Bristow and Capt I Evans of tiec "Careflight" team.

\section{REFERENCES}

1. MOYLAN J A. Impact of helicopters on trauma cade and clinical results. Ann Surg 1988; 208(6): 673

2. Scholl M D, Geshekter C L. The Zed Expediticio: the world's first air ambulance? $J R$ Soc Med 1989; 8 : 679.

3. Hankins D G, Frascone R J. The helicopter and tiee

EMS System. Minn Med 1988; 71: 700 .
4. Cook J L. Dust Off. New York: Bantam Books 1988.

5. FELIX W R. Metropolitan aeromedical service: sta of the art. J Trauma 1976; 16(11): 873.

6. Leading article. Helicopters and medical emerge cies. Br Med J 1968; 2(608): 778. 
7. Moylan J A, Fitzpatrick K T, Beyer A J, et al. Factors improving survival in multisystem trauma patients. Ann Surg 1983; 207(6): 679.

8. DUKE J H, Clarke W P. A university-staffed, private hospital-based air transport service. The initial twoyear experience. Arch Surg 1981; 116(5). 703-8.

9. MCNeIL E L. Airborne Care of the Sick and Injured. New York: Springer-Verlag, 1982.

10. Champion H R. Helicopters in emergency trauma care. IAMA (Editorial) 1983: 249(22): 3074.

11. BAXt W G, Moody P. The impact of a rotorcraft aero-medical emergency care service on trauma mortality. JAMA 1983; 249: 3047.

12. Rhee $\mathrm{K}$ J, Willits $\mathrm{N}$ H, Turniz J E, Ward R E. Trauma score during transport: is it predictive of mortality? Am J Emerg Med 1987; 5(5): 353.
13. Noy-Man Y, Hornung S, Barbash G, Margaliot S. Medical Air Evacuation during the Lebanon War, 1982. Israel J Med Sc 1984; 20: 303.

14. Jolly R. The Red and Green Life Machine. London: Century Publishing Co. Ltd., 1983.

15. GREEN D. Service reaches new heights. In: Supplement to the Health Service Journal. 1989 May, 1.

16. GOOLD D. First-aid fliers. Flight International, Nov 1987, 22.

17. Kee S, Ramage C, Bristow A. The movement of the critically ill patient between hospitals. Care of the Critically Ill 1989; 5: 200.

18. Botha A J, Earlam R J, Wilson A W et al. The Royal London Hospital Helicopter Emergency Service: First Phase 1990. Suppl Ann R Coll Surg Eng 1992; 74(5): 130 . 